\title{
A new approach for social vulnerability in mainland Portugal area for risk mitigation
}

\author{
A.O. Tavares \\ Earth Sciences Department, Center for Social Studies, University of Coimbra, Portugal \\ J.L. Barros, P.P. Santos \& J.M. Mendes \\ Center for Social Studies, University of Coimbra, Portugal
}

\begin{abstract}
The concept of Social Vulnerability (SV) is characterized by its multidimensionality. In the present study, Social Vulnerability was analyzed and evaluated according to the methodology developed by the Center for Social Studies of the University of Coimbra, which presents as innovative feature the incorporation of the Criticality and Support Capability components. Social Vulnerability was calculated for the 278 municipalities of mainland Portugal using factor analysis. The evaluation and calculation of the Criticality was carried out using 22 variables, selected from an initial number of 90, and the calculation of Support Capability was performed using 12 variables, from an initial number of 145 variables. The obtained outputs should be a working basis for the managers and stakeholders, authorities at different levels, and all the community with the objective of adopting adaptation and mitigation measures to natural and technological risks.
\end{abstract}

\section{INTRODUCTION}

The concept of Social Vulnerability (SV) is characterized by its multidimensionality, adding not only the social characteristics of the individual, but also their social and economic relations, as well as the physical and social environment where the individual is inserted (Tapsell et al., 2010). The differentiating characteristics of SV make it imperative not only in the characterization and understanding of the degree of exposure of the communities, but also in their capacity for resisting and recovering in face of hazardous events.

Historically, the concept of Social Vulnerability has emerged as an explicit critique of the dominant and conventional paradigms of analysis of disasters, with Hewitt (1983). The Sendai Framework for Disaster Risk Reduction resumes the concept of vulnerability as the conditions determined by the physical, social, economic and environmental factors or processes that increase the susceptibility of a community to the impact of hazards (UNISDR, 2015). Thus, the scientific community as recognized the need of considering social vulnerability as a particular dimension of vulnerability, developing distinct approaches for its measurement (e.g., Angeon and Bates, 2015; Rufat et al., 2015; Fatemi et al., 2017).

As noted by Wisner et al. (2004) the vulnerability to hazards is a multidimensional process that consists in a multiplicity of components related with historical, political, economic, environmental and demographic factors, which produce inequalities, dynamic pressures such as rapid urbanization and social pressures and unsafe living conditions that originates unequal exposure to risk.

There are multiple and distinct methods of measuring vulnerability (Birkmann, 2006; Fuchs et al., 2012; Birkmann, 2013; Birkmann et al., 2013;). In the present work, Social Vulnerability to natural and technological risks was analyzed and evaluated according to the methodology developed by the Center for Social Studies of the University of Coimbra (CES) and its Risk Observatory (OSIRIS) (Mendes et al., 2011). According to Mendes et al. (2011) the concept of $\mathrm{SV}$ is associated with the degree of exposure to natural and technological hazards and extreme events, depending closely on the resilience of individuals and communities.

Social Vulnerability must be a planning tool, supporting the implementation of a territorial model in which decision-making on risk management would be more efficiently applied.

The study is divided into 5 sections: a) Presentation of the area of study; b) methodology for the calculation of Social Vulnerability and its components; c) results at municipal level; d) discussion of the results; e) conclusions of study. 


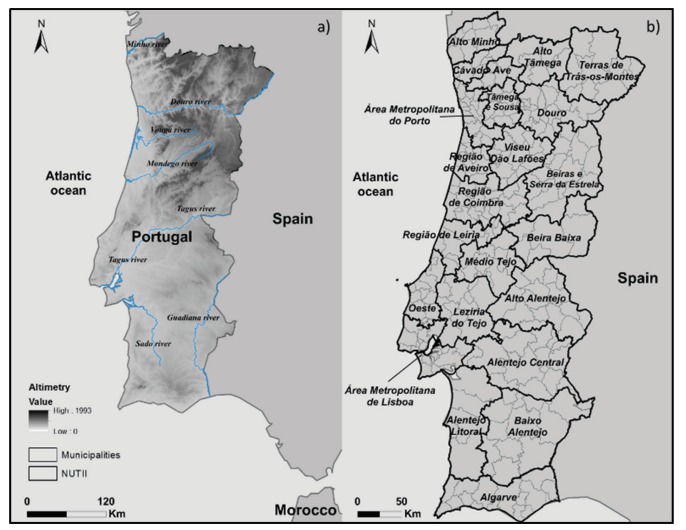

Figure 1. Location of the studied area: a) Continental Portugal (NUT I); b) Territorial organization in NUT II and LAU I (municipalities).

\section{STUDY AREA}

The present study was based on the calculation of SV for the 278 municipalities of mainland Portugal, with a total area of $89,089 \mathrm{Km}^{2}$ and a resident population of 10,044,484 inhabitants according to the 2011 Census (INE, 2012). In administrative terms Portugal is divided into three NUTS (Nomenclature of Territorial Units for Statistics) which is subdivided into three levels, defined according to population, administrative and geographical criteria and in two LAU (Local Administrative Unit), in accordance with Decree-Law 244/2002, changed in 2015 by regulation $n^{\circ} 868$ / 2014. The work presented here supports its analysis at the level of NUT III, which is composed of 23 territorial units and LAU I, which is composed of 278 municipalities (Figure 1b).

\section{METHODOLOGY}

The principal objective of this work is to evaluate the Social Vulnerability at municipal level in mainland Portugal. This evaluation will be assessed using principal component analysis (PCA), a technic also used by different authors like Cutter et al. (2003), Schmidtlein et al. (2008), Mendes (2009), Barros et al. (2015), with adaptations according to regional and local specificities, expressed in the type of variables and unit of analysis to be selected. For PCA was used the software SPSS ${ }^{\circledR}$, version 23 . The data that supports this evaluation were obtained using information from the Census 2011 (INE, 2012) and PORDATA database (PORDATA, 2017). In this study the conceptual understating of Social Vulnerability defined by Mendes et al. (2011) was adopted, where SV is composed by two components: Criticality and Support Capability. The evaluation of Social Vulnerability was based on PCA where redundant variables are eliminated and the remaining are normalized and grouped into factors. The PCA was carried out based on a set of premises where it stands out: a) the calculation of the Pearson correlation matrix analysis; b) the variance rate parameters (should be greater than 60\%) and the Kaiser-MeyerOlkin (KMO) sample measurement (should be greater than 0.6) with the purpose of eliminating redundant data (Comrey et al., 2009) and select the more PCA-robust dataset; c) the use of Varimax rotation to better identify the principal components. This process is done for both Criticality and Support Capability. After obtaining the respective scores in each municipality, Social Vulnerability is calculated by combining the two components mentioned above using the following equation:

$$
\text { Social Vulnerability }=\underset{\text { Capability })}{\text { Criticality }} \times(1-\text { Support }
$$

The results obtained are grouped into different classes that vary from very low to very high in accordance with the standard deviation (SD) and the following categories: "very low," <1 SD; "low," [-1, -0.5 SD]; "moderate," [-0.5, +0.5 SD]; "high," [0.5, $1 \mathrm{SD}]$; "very high," $\geq 1 \mathrm{SD}$ (Cutter et al. 2003).

\subsection{Criticality}

The calculation of Criticality for all municipalities of mainland Portugal was carried out using 22 variables grouped into seven groups (Table 1). PCA identified 6 factors (FAC) based in the 22 explicative variables. These factors present a variance rate of $73 \%$ for the 278 municipalities under study, with a KMO of 0.726 and all communalities above 0.6.

\subsection{Support capability}

The Support Capability was performed using 12 variables grouped into four groups (Table 2).

Table 1. Groups of variables used in the calculation of municipal criticality.

\begin{tabular}{ll}
\hline Groups & Number of variables \\
\hline Social support & 3 \\
Housing conditions & 2 \\
Demography & 2 \\
Economy & 9 \\
Education & 2 \\
Housing & 3 \\
Health & 1 \\
\hline
\end{tabular}


Table 2. Groups of variables used in the calculation of municipal support capability.

\begin{tabular}{ll}
\hline Groups & Number of variables \\
\hline Economy & 4 \\
Civil protection resources & 4 \\
Building characteristics & 2 \\
Health facilities & 2 \\
\hline
\end{tabular}

Table 3. Criticality components.

\begin{tabular}{lll}
\hline FAC & Name & $\begin{array}{l}\text { Explained } \\
\text { variance (\%) }\end{array}$ \\
\hline 1 & Risk groups & 30 \\
2 & Economic conditions & 13 \\
3 & Disadvantaged population & 12 \\
4 & Level of income & 7 \\
5 & Employment & 6 \\
6 & Dependent population & 5 \\
\hline
\end{tabular}

Based on the variables presented in Tables 2, 3 FAC's were retained, presenting a variance rate of $65 \%$ for the 278 municipalities under study, with a KMO of 0.705 and all communalities above 0.6.

\section{RESULTS}

\subsection{Factors of criticality}

As mentioned above the Criticality assessment identified 6 factors with different percentages in the explained variance (Table 3 ).

\subsubsection{Factor 1-Risk groups}

The factor named "Risk Groups" explains 30\% of the model variance where the proportion of the population under 5 years old is the dominant variable. This factor describes the most vulnerable population through the variable mentioned above and this FAC is also explained by the following variables: proportion of population with difficulties; proportion of students by secondary educational establishment and students by pre-school educational establishments. The FAC 1 is also composed by variables that are related with housing, namely: the proportion of rented accommodation and the proportion of seasonal housing. These characteristics are important because according with Cutter et al. (2003) and Mendes et al. (2011) the type of accommodation in which an individual resides reflects, in most cases, their personal, social and economic characteristics. The last variable in this factor is the average value of social security pensions which allows identifying economically and financially fragilized populations.

\subsubsection{Factor 2 - Economic conditions}

The factor 2 explains $13 \%$ of the variance where the proportion of employees on behalf of others is the dominant variant. This FAC is also constituted by the following variables: proportion of selfemployed workers as an isolated employer; proportion of self-employed workers; persons employed in the primary sector; average value of social protection pensions; proportion of seasonal households. In this FAC it is considered that the better the economic condition, the greater the capacity to face and recover from hazardous events.

\subsubsection{Factor 3 - Disadvantaged population}

Factor 3 is related with the disadvantaged people and contributes with $12 \%$ of the model variance. The variable dominant is beneficiaries of the Social Integration Income (RSI) and Minimum Guaranteed Income (RMG). The proportion of housing units with renting below 100 euros, the proportion of buildings built before 1919 and the proportion of employed population in the primary sector are the other variables present in this FAC. This FAC represent, in the most cases, the population with low-income, low socio-professional and highly economic and social dependent on institutional aid.

\subsubsection{Factor 4-Level of income}

Factor 4 explains $7 \%$ of the variance and is composed by the following variables: customer deposits in banks, savings banks and mutual agricultural credit, which is the dominant variable, and purchasing power ratio. This factor is related with the economic capacity of the population.

\subsubsection{Factor 5 - Employment}

This factor explains $6 \%$ of total variance and is composed by two variables: the proportion of employed population in the tertiary sector (dominant variable) and proportion of population employed in the secondary sector.

\subsubsection{Factor 6 - Employment}

Factor 6 explains 5\% of the variance and is composed only by the variable proportion of social housing supported by social and supported income, being directly related with economic power of the population.

\subsection{Criticality factors' cartography}

The analysis of the factor 1 (Figure 2) shows that the highest values related with risk groups are located mainly in the municipalities of the central and inland areas of Portugal. This fact is directly related, in the most cases, with the areas where high percentages of elderly population and low percentages of young population are observed. In factor 2 , a clear distinc- 
tion is observed between the north and south areas (highest values) with the center region. These highest values of criticality related with low economic conditions are located, essentially, in the municipalities belonging to NUT III of Alto Tâmega, Terras de Trás-os-Montes and Douro (in the north) and in the Baixo Alentejo, Alentejo Litoral and Algarve southern areas, where the primary sector still plays a very important role in the regional economy.

There are also areas where there is an important proportion of self-employed workers as an isolated employer and the proportion of self-employed workers, mostly related with the primary sector. Factor 3 is related with disadvantaged population, and we can observe in the Figure 2 that the highest values of this factor emerge along the val-

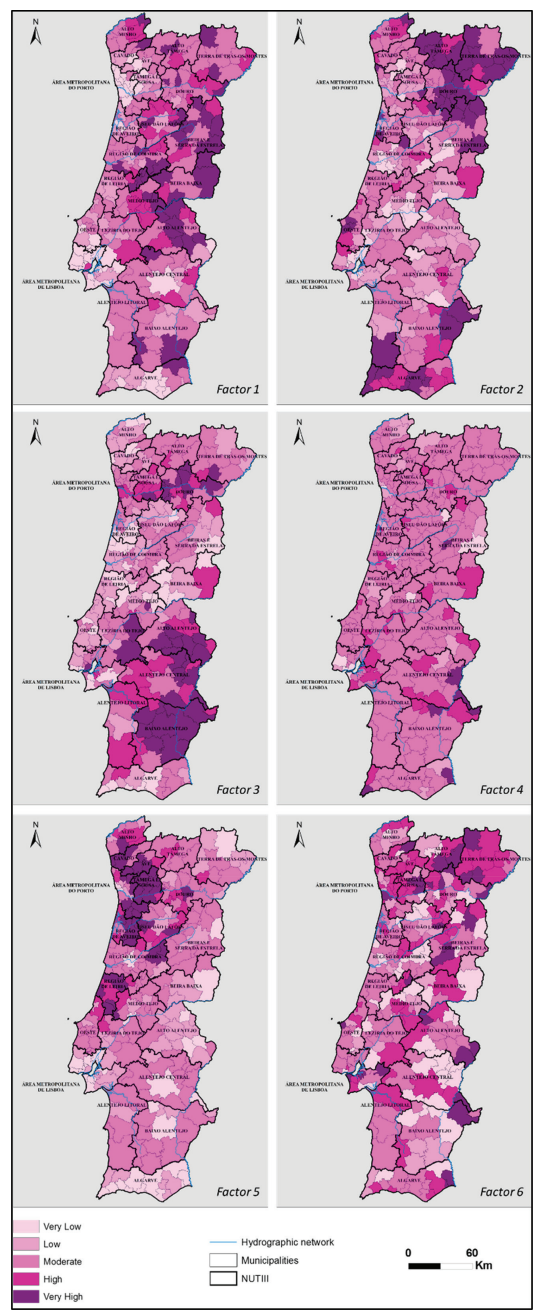

Figure 2. Cartography of the three factors that compose the criticality. ley of Douro river and south of the Tagus river in municipalities with high percentages of population beneficiary of the RSI and RMG, living in lowrent housing and old buildings and work in the primary sector.

The analysis of cartography of factor 4 , named level of income, allows concluding that a great territorial homogeneity exists in the different variables that compose this factor. In factor 5, related with employment, namely the population employed in secondary and tertiary sector. In this analysis we considered that employment in the secondary sector are more vulnerable. This fact is related with the predomination of small and medium enterprises, with value added (VAB) lower than tertiary sector and with greater fluctuation in productivity and employment in time of crises. The cartography identifies the highest values in the coastal northern zone of Tagus river highlighting NUT III Região de Leiria, Região de Aveiro, Área Metropolitana do Porto, Tâmega e Sousa, Cávado e Ave, which stand out as areas with strong industrial and commercial dynamism. The factor dependent population (factor 6) presents highest values north of the Tagus river, and mainly those municipalities on the right margin of the Douro river.

\subsection{Factors of support capability}

The Support Capability assessment identifies 3 factors that resulted from PCA with different percentages in the explained variance (Table 4).

\subsubsection{Factor 1 -Civil protection resources}

The factor 1 explains $30 \%$ of the total variance and is related with the municipal civil protection capability. The dominant variable is the number of fire-fighter corporations per 1000 inhabitants. The other variables of the model are: firefighters per 1000 inhabitants, average number of inhabitants per covered spaces (which represents shelter facilities), pharmacies per 10000 inhabitants and density of road network.

\subsubsection{Factor 2 - Economic an environmental dynamic}

This factor explains $22 \%$ of the variance and is composed by the following variables: urban waste

Table 4. Support capability components.

\begin{tabular}{lll}
\hline FAC & Name & $\begin{array}{l}\text { Explained } \\
\text { variance (\%) }\end{array}$ \\
\hline 1 & $\begin{array}{l}\text { Civil protection resources } \\
\text { Economic and environmental } \\
\text { dynamic }\end{array}$ & 30 \\
3 & Logistics and services capacity & 12 \\
\hline
\end{tabular}


collected, in kg per inhabitant, proportion of collective households, ATMs per 1000/inhabitants and accommodation capacity in hotel establishments per 1000 inhabitants, which is the dominant variable.

\subsubsection{Factor 3-Logistics and services capability}

This factor is related with the economic dynamism and explains $12 \%$ of the variance. The dominant variable is ATMs per 1000 inhabitants. The other variables that compose the factor 3 are hospitals per 1000 inhabitants and insurance agencies per 1000 inhabitants.

\subsection{Support capability factors cartography}

Figure 3 shows the cartographic representation of each FAC expressing Support Capability.

Factor 1 is related with civil protection resources and with the analysis of the Figure 3 we can observe that the lowest values are located in the metropolitan Lisboa and Porto areas, as well as in adjacent municipalities. This factor is directly related with population density where a relatively

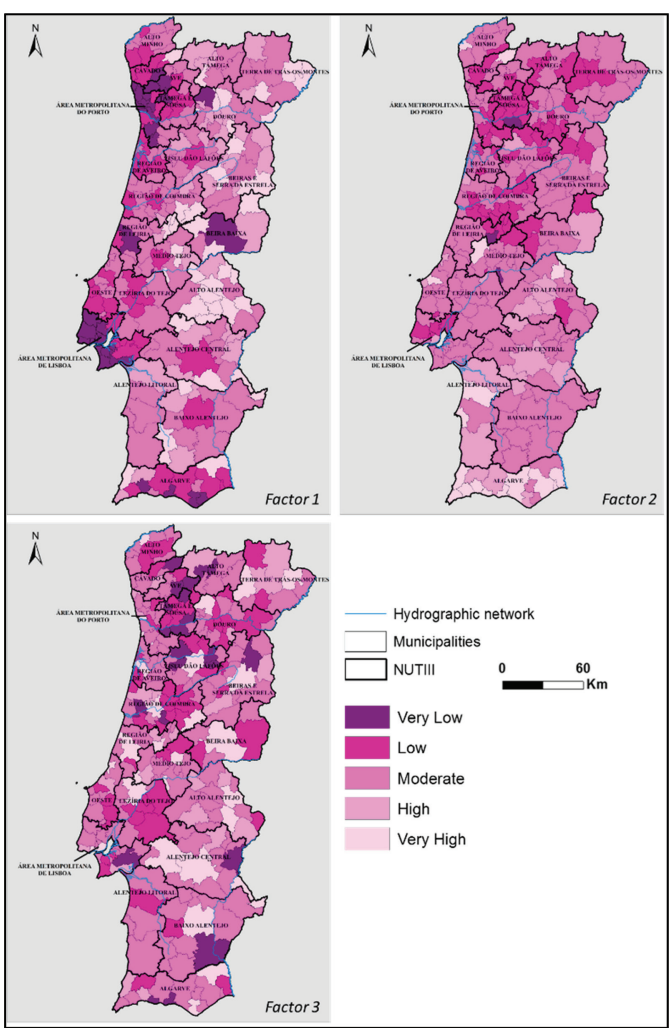

Figure 3. Cartography of the three factors that compose the suport capability. reduced number of resources serves a greater number of inhabitants, when compared with less urbanized areas. The factor economic an environmental dynamic (factor 2) express mainly the urban character of the different municipalities. We can observe that the majority of the municipalities analyzed presents moderate values, with the lowest values principally concentrated in the northern margin of the Tagus river.

\subsection{Criticality at municipal level}

Figure 4 presents the cartographic representation of Criticality for mainland Portugal.

We can observe that the lowest values or Criticality are mainly concentrated in the coastal area, especially in the Algarve region, and in the main regional capitals of Lisboa, Leiria, Coimbra and Porto, and their neighboring municipalities. The highest values arise predominantly at northern

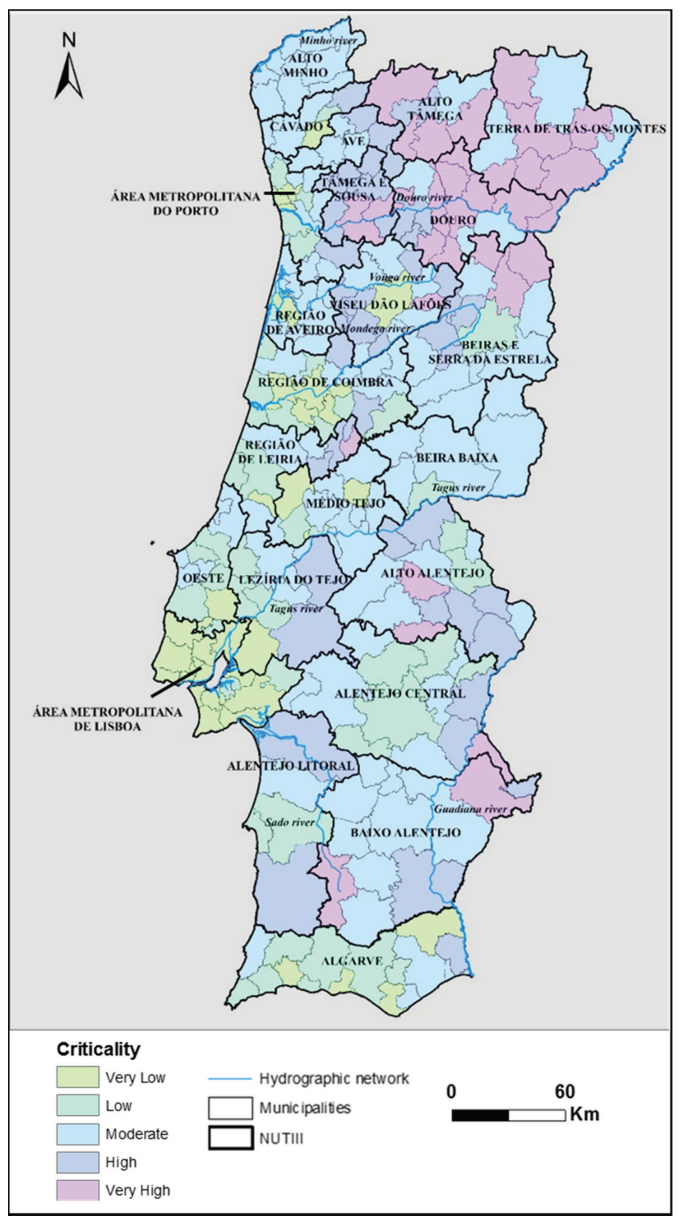

Figure 4. Criticality in mainland Portugal. 
municipalities, namely in Alto Tâmega, Trás-osMontes and along the Douro river valley. We also observe high Criticality values in the central region of Portugal, where stands out the surrounding municipalities of Viseu (located in NUTT III Viseu Dão Lafões), and along the border with Spain in the municipalities belonging to NUT III of Alto Alentejo, Alentejo Central and Baixo Alentejo.

\subsection{Support capability at municipal level}

Figure 5 shows the cartographic representation of each FAC belonging to Support Capability.

The analysis of Figure 5 allows observing that the metropolitan area of Lisboa (with the exception of the municipality of Lisboa and Oeiras) and Porto (with the exception of the municipality of Porto) presents very low and low values of Support Capability. This fact is also noted in the majority

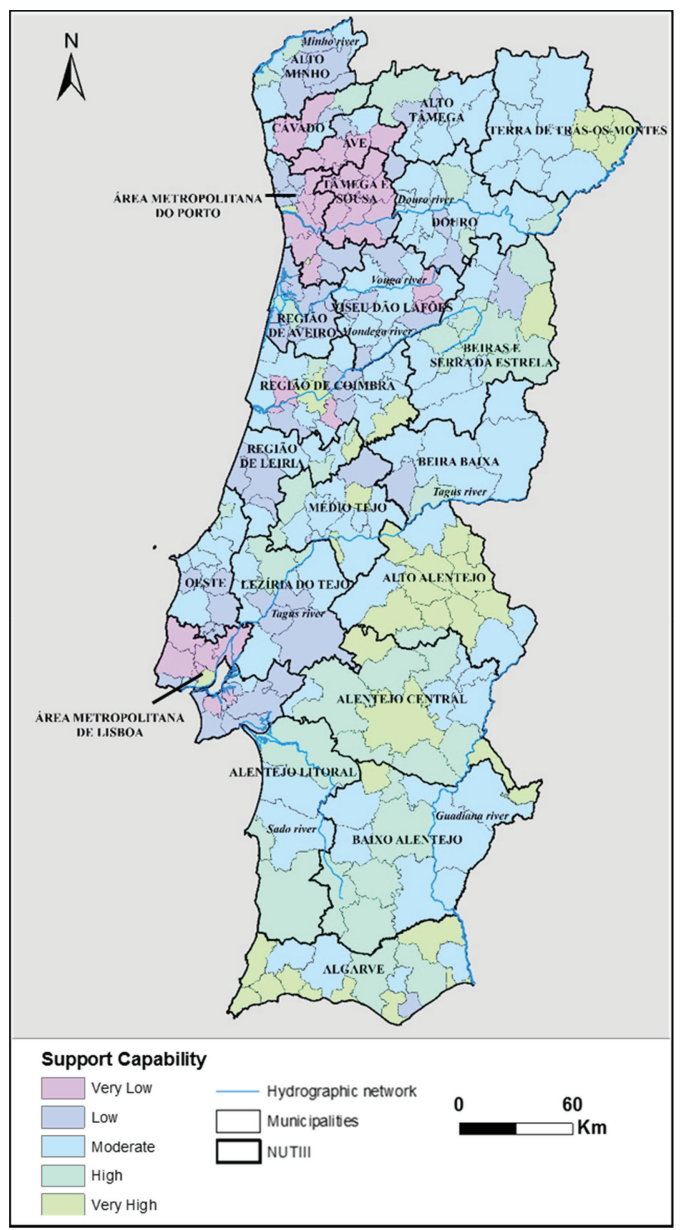

Figure 5. Support capability in mainland Portugal. of municipalities and NUT III surrounding these areas. This fact permits to conclude that, in most cases, such low values are directly related with high population density. On the other hand, we observe that the highest values are predominantly located in the inland municipalities, especially in areas south of the Tagus river, in municipalities characterized by the availability of the resources for a small number of inhabitants.

\subsection{Social vulnerability at municipal level}

The application of equation 1 that combines the Criticality and Support Capability results in the calculation of Social Vulnerability for the 278 municipalities of mainland Portugal. The analysis allows observe that the highest values of Social Vulnerability are concentrated in the northern areas, namely in municipalities located along the Douro river valley, in the region of Tâmega and Sousa, Ave, southern area of the Porto metropolitan area, Alto Tâmega, Terras de Trás-os-Montes and Viseu Dão Lafões.

In terms of lowest values we can observe that they are concentrated in areas in southern part of the country where stands outs the region of Baixo Alentejo and Algarve where the majority of municipalities has values of Social Vulnerability ranging from low to very low.

\section{DISCUSSION}

The analysis and evaluation of Social Vulnerability allows to conclude that we can divide, in general terms, the mainland Portugal in two areas: the area at north and the area at south of the Tagus river where the high and very high values are mainly located in the northern part. The reasons for this spatial distribution depends on several factors.

In terms of Criticality the most important factors at the municipal level are those related with the risk groups, the economic conditions and the disadvantaged population. In the total of 278 municipalities we observe that $40 \%$ of them present moderate Criticality, $30 \%$ values that varies from very low to low and 30\% varying from high to very high.

About the Support Capability we can observe a relation between the highest values and the high density of population. The most important factors are associated with variables related to the civil protection resources (factor 1) and variables related to economic and environmental dynamics (factor 2). We also conclude that $39 \%$ of analyzed municipalities presents moderate Support Capability, $34 \%$ values that varies from very low to low and $27 \%$ varying from high to very high. 
In terms of Social Vulnerability it possible to conclude that the final values are strongly influenced by factors related with the weak economic power of the resident population, the fragility of its economic fabric and the presence of significant percentages of dependent and disadvantaged population.

The present methodology allows compare and differentiate regions and municipalities in terms of whose characteristics of criticality, capacity of support and social vulnerability would not be evidenced in another way. The spatialization of each component and associated variables are important for the definition, application and promotion of measures related with social policies, housing, distribution and reinforcement of collective equipment, the implementation of a model of economic development more balanced in terms of employment in the inland areas and urban planning policies. The implementation and the success of this measures are important to reduce asymmetries between regions and municipalities. For the success of this measures are important promote and encourage the inter-municipal resource sharing in the sense of corresponding to the character multidimensional and multidisciplinary of Social Vulnerability and associated components.

\section{CONCLUSIONS}

The present work presents the calculation of Social Vulnerability for the total of 278 municipalities of mainland Portugal in accordance with the methodology presented by Mendes et al. (2011). The character multidimensional of this methodology that combine the Criticality and Support Capability allows not only the calculation of Social Vulnerability as also because of its strong territorial component, defining the Territorial Vulnerability of the analyzed areas.

The multidimensionality of this study, that is based in an extended set of variables from various dimensions like social support, housing, demography, economy, education and health allows the applicability in several risk governance dimensions. The cross-referencing of these data with existing regional or local information may result in programs that promote capacity and social cohesion. The outputs resulting from the present study allow the observation and comparison, among different places. This fact can and should be a work tool for analysis and application by different stakeholders, from multiple sectors and authorities at national, regional and local level.

The knowledge and the consciousness of the territorial distribution of Social Vulnerability and its components (Criticality and Support
Capability) as well as their consideration in risk management-where spatial planning instruments are a central part of the process, is a key tool for the definition and application of multidisciplinary and multi-scale risk management strategies that not only consider the physical aspects of the territory, but all its social and institutional dimensions. In fact, the implementation of municipal and local measures that address high SV contexts would first require the existence of an adequate institutional building, drawn upon the best risk governance practices.

\section{ACKNOWLEDGMENTS}

This work was financed by national funds through FCT-Portuguese Foundation for Science and Technology, I.P., under the framework of the project FORLAND - Hydro-geomorphologic risk in Portugal: driving forces and application for land use planning (PTDC/ATPGEO/1660/2014).

\section{REFERENCES}

Angeon, V. \& Bates, S. 2015. Reviewing Composite Vulnerability and Resilience Indexes: A Sustainable Approach and Application. World Development, 72: 140-162.

Barros, J.L., Tavares, A.O., Santos, A., Fonte, A. 2015. Territorial vulnerability assessment supporting risk managing coastal areas due to tsunami impact. Water. 7:4971-4998.

Birkmann, J. 2006. Measuring vulnerability to promote disaster-resilient societies: Conceptual frameworks and definitions, Measuring Vulnerability to Natural Hazards; Towards Disaster Resilient Societies, 1:9-54.

Birkmann, J. 2013 Measuring vulnerability to natural hazards. Tóquio: United Nations University Press.

Birkmann, J., Cardona, O. D., Carreño, M. L., Barbat, A. H., Pelling, M., Schneiderbauer, S., Kienberger, S., Keiler, M., Alexander, D., Zeil, P. \& Welle, T. (2013). Framing vulnerability, risk and societal responses: The MOVE framework. Natural Hazards, 67(2) 193-211.

Comrey, A., \& Lee, H. 2009. A first course in factor analysis. New York: Physiology Press.

Cutter, S. L., Boruff, B. J., \& Shirley, W. L. 2003. Social vulnerability to environmental hazards. Social science quarterly. 84(2): 242-261.

Fatemi, F., Ardalan, A., Aguirre, B., Mansouri, N. \& Mohammadfam, I. 2017. Social vulnerability indicators in disasters: Findings from a systematic review. International Journal of Disaster Risk Reduction, 22: 219-227.

Fuchs, S., Birkmann, J., \& Glade, T. 2012. Vulnerability assessment in natural hazard and risk analysis: current approaches and future challenges. Natural Hazards, 64(3): 1969-1975.

Hewitt, K. 1983. Interpretations of Calamity from the Viewpoint of Human Ecology. London: Allen and Unwin.

INE. 2012. Censos 2011 Resultados Definitivos e Portugal. Lisbon: National Institute of Statistics. 
Mendes, J. M., Tavares, A. O., Cunha, L., \& Freiria, S. 2011. A vulnerabilidade social aos perigos naturais e tecnológicos em Portugal. Revista Crítica de Ciências Sociais. 93: 95-128.

Mendes, J.M. 2009. Social Vulnerability Indexes as Planning Tools: Beyond the preparedness paradigm. Journal of Risk Research, 12:43-58.

PORDATA. 2017. Base de dados Portugal Comtemporâneo. Available at:http://pordata.pt. Acessed August, 2017.

Rufat, S., Tate, E., Burton, C. G., \& Maroof, A. S. 2015. Social vulnerability to floods: Review of case studies and implications for measurement. International Journal of Disaster Risk Reduction, 14:470-486

Schmidtlein, M., Deutsch, R., Piegorsch, W., \& Cutter, S. 2008. A sensitivity analysis of the Social Vulnerability Index. Risk Analysis, 28: 1099-1114.
Tapsell, S., McCarthy, S., Faulkner, H., Alexander, M 2010. Social Vulnerability to Natural Hazards. CapHazNet WP4 Report, Flood Hazard Research CentreFHRC, Middlesex University, Londres. Acessível em http://caphaz-net.org/outcomes-results/CapHaz - Net_ WP4_Social-Vulnerability.pdf

UNISDR 2015. Sendai Framework for Disaster Risk Reduction 2015-2030. United Nations Office for Disaster Risk Reduction, Sendai, Japan.

Wisner, B., P. Blaikie, T. Cannon, and I. Davis 2004. At Risk: Natural Hazards, People's Vulnerability and Disasters. 2nd ed. London: Routledge. 